\title{
PARANGOLÉS DE AÇÕES E CICLO DE AÇÕES COLETIVO: Uma Proposta Teórica para Discutir Interações e Aprendizagem com o Uso de Lousa Digital
}

\author{
Sérgio Freitas de Carvalho ${ }^{1}$ \\ Suely Scherer ${ }^{2}$
}

\begin{abstract}
RESUMO
Este artigo objetiva apresentar e discutir uma proposta de articulação teórica para analisar interações e movimentos de aprendizagem com o uso de Lousa Digital. Trata-se de uma proposta teórica denominada Ciclo de Ações Coletivo, que articula estudos de José Armando Valente sobre o Ciclo de Ações ao realizar atividades usando o computador, e estudos de Jaan Valsiner sobre a Psicologia Cultural, especialmente a aprendizagem compreendida a partir de processos de internalização e externalização de mensagens. A obra Parangolé, de Hélio Oiticica, oportunizou o encontro com a representação de uma das ações vivenciadas na construção teórica proposta - os movimentos denominados Parangolés de Ações. Essa construção teórica, o Ciclo de Ações Coletivo (Parangolé de Ações - Descrição - Execução), pode orientar ações com a Lousa Digital em sala de aula de diferentes disciplinas. As análises de interações e aprendizagens a partir desta construção teórica evidenciaram que as formas e cores dos Parangolés de Ações estão associadas às interações vivenciadas pelos indivíduos por meio de suas internalizações e externalizações. Assim, evidencia-se, portanto, a importância de se pensar um uso da Lousa Digital que favoreça a aprendizagem, a partir de interações, para a constituição de Parangolés de Ações cada vez mais coloridos.
\end{abstract}

Palavras-chave: Lousa Digital. Aprendizagem. Ciclo de ações. Parangolés de ações.

PARANGOLÉS OF ACTIONS AND COLLECTIVE ACTIONS CYCLE:

A THEORETICAL PROPOSAL TO DISCUSS INTERACTIONS AND LEARNING USING THE DIGITAL WHITEBOARD

\section{ABSTRACT}

This article aims to present and discuss a theoretical articulation proposal to analyse interactions and learning movements with Digital Whiteboard use. This is a theoretical proposal called the Collective Actions Cycle, which articulates studies by José Armando Valente, about the Cycle of Actions when performing activities using the computer, and studies by Jaan Valsiner, on Cultural Psychology, especially learning understood from the processes of internalization and externalization of messages. The work Parangolé, by Hélio Oiticica, offered the opportunity to meeting with the representation of one of the actions experienced in the proposed theoretical construction, the movements called Parangolés de Ações. This theoretical construction, the Collective Actions Cycle (Parangolé of Actions - Description - Execution) can guide actions with Digital Whiteboard use in the classroom of different disciplines. The analyzes of interactions and learnings carried out from this theoretical construction showed that the shapes and colors of the Parangolés of Actions are associated with the interactions experienced by individuals, through their internalizations and externalizations. Thus, it is evident, therefore, the importance of thinking about a Digital Whiteboard use that favors learning from interactions, for the constitution of increasingly colorful Parangolés of Actions.

Keywords: Digital Whiteboard. Learning. Actions Cycle. Parangolés of actions.

RECEBIDO EM: 27/12/2019

ACEITO EM: 20/4/2020

\footnotetext{
${ }_{1}$ Autor correspondente. Instituto Federal de Mato Grosso do Sul. Campus Nova Andradina. Rodovia MS 473, Fazenda Santa Bárbara. CEP 79750-000 - Nova Andradina/MS, Brasil. http://lattes.cnpq.br/3276349142458228. http://orcid.org/0000-0002-4672-4720"0000-00024672-4720. sergiofdcarvalho2012@gmail.com.

2 Universidade Federal de Mato Grosso do Sul. Cidade Universitária, Avenida Costa e Silva-Pioneiros, Campo Grande/MS, Brasil. CEP 79070-900. http://lattes.cnpq.br/6812065936018405. https://orcid.org/0000-0002-2213-3803. suely.scherer@ufms.br
} 
No cenário de pesquisa que se constitui acerca do uso de tecnologias digitais em processos de ensino e de aprendizagem, é possível encontrar investigações realizadas em direções distintas, por exemplo, em processos de aprendizagem com o uso de tecnologias, formação de professores para o emprego de tecnologias digitais, currículo e práticas educativas com uso de tecnologias, dentre outras. Cada uma dessas temáticas, por sua vez, abre possibilidades para novos estudos e pesquisas e, assim, possibilita diferentes investigações que ajudam a compor o cenário investigativo sobre tecnologias educacionais, em especial as digitais.

Este artigo, que é um dos resultados de uma tese de Doutorado (CARVALHO, 2019), situa-se, inicialmente, na direção de pesquisas que versam sobre processos de aprendizagem com uso de tecnologias, considerando-se especificidades da Lousa Digital. Parte-se do pressuposto de que a tecnologia digital discutida aqui - a Lousa Digital - possui especificidades que fazem do seu uso um campo de investigação com características próprias, seja para a formação de professores para a utilização desta tecnologia, para processos de aprendizagem com a mesma, ou outras. Considerando-se este contexto, propõe-se, portanto, uma discussão teórica acerca de processos de aprendizagem com uso da Lousa Digital.

A pesquisa, cujo resultado - um deles - apresentamos neste artigo, teve por objetivo investigar movimentos de aprendizagem com uso de Lousa Digital em aulas de Matemática. Para a investigação em questão, desenvolvida junto ao Programa de Pós-Graduação em Educação Matemática da Universidade Federal de Mato Grosso do Sul - UFMS -, foram produzidos dados com turmas de alunos de Ensino Fundamental e Ensino Médio em escolas públicas de Campo Grande - Mato Grosso do Sul - utilizando a Lousa Digital em aulas de matemática.

A produção de dados ocorreu no segundo semestre de 2016 e no primeiro de 2017. Foram desenvolvidas aulas de matemática utilizando a Lousa Digital em uma turma de oitavo ano do Ensino Fundamental, na qual o pesquisador era também o professor da turma, e em uma turma de Ensino Médio (que, em 2016, cursava o primeiro ano e, em 2017, o segundo), por meio de uma parceria com o professor da turma em questão.

Com a turma de oitavo ano, utilizando a Lousa Digital em conjunto com o software Geogebra, foram desenvolvidos estudos sobre coordenadas cartesianas, paralelismo, perpendicularidade e triângulos (condição de existência, classificações, propriedades). Com a turma de Ensino Médio realizou-se estudos sobre área de figuras planas, utilizando a Lousa Digital e o Geoplano Digital, bem como estudos sobre trigonometria com o uso do Geogebra.

Para fins de registros, todas as aulas foram gravadas em áudio e vídeo que, aliados aos registros de observação do pesquisador, constituíram os dados da pesquisa; dados estes que foram produzidos, analisados e discutidos a partir de uma articulação teórica construída na tese, que é objeto de discussão deste artigo. Como construção teórica, a discussão que propomos pode orientar ações com uso da Lousa Digital em diferentes aulas.

A proposta teórica que se apresenta neste artigo é denominada Ciclo de Ações Coletivo (Parangolé de Ações - Descrição - Execução). Esse Ciclo é um caminho para propor e analisar a aprendizagem, compreendida aqui como processo de construção coletiva de conhecimento com o uso da Lousa Digital em sala de aula. A proposta foi cons- 
truída a partir de estudos de José Armando Valente (2005), sobre o Ciclo de Ações no uso de computadores, e de Jaan Valsiner (2012), sobre aprendizagem na perspectiva da Psicologia Cultural. Uma das ações do Ciclo proposto (Parangolé de Ações - Descrição - Execução) é representada por Parangolés inspirados na obra do artista plástico Hélio Oiticica, que foi utilizada como metáfora no desenvolvimento da tese. Assim, apresenta-se neste artigo a construção teórica realizada, partindo de elementos teóricos orientadores e da discussão de elementos da metáfora do Parangolé.

\section{ELEMENTOS TEÓRICOS}

Discutir aprendizagem com uso da Lousa Digital implica pensar nas características e particularidades dessa tecnologia e em como tais características podem influenciar processos de aprendizagem.

No âmbito deste artigo e da pesquisa desenvolvida, entende-se a Lousa Digital como uma "grande tela de computador" com a qual se tem a possibilidade de oportunizar momentos de construção coletiva de conhecimentos em sala de aula com o uso desta tecnologia digital. Isso deve-se ao fato de vários sujeitos poderem trabalhar ao mesmo tempo com o "mesmo computador", seja indo até a Lousa e operando-a manualmente ou por meio de proposições orais ao interagir com colegas (como retorno ao que foi proposto, e/ou do que se viu em tela).

As características e particularidades da Lousa Digital, portanto, nos levam a refletir sobre a importância de se lançar sobre a questão da aprendizagem com tecnologias digitais um olhar específico, um olhar que parte da perspectiva do aprender em interação com o outro. Nesse sentido, com o estudo que realizamos chegou-se ao movimento de um "Ciclo de Ações Coletivo", uma proposta de articulação teórica para analisar movimentos de aprendizagem com Lousa Digital em sala de aula que construímos na tese a partir de elementos do Ciclo de Ações de Valente (2005), da Psicologia Cultural (VALSINER, 2012) e da obra Parangolé, do artista plástico Hélio Oiticica.

O Ciclo de Ações de Valente (2005), juntamente com elementos da Psicologia Cultural (VALSINER, 2012), tem norteado estudos que perpassam por diferentes aspectos da questão da aprendizagem com tecnologias digitais. Um estudo que podemos citar é o de Oliveira (2019), que investigou o processo de estruturação de conhecimentos de geometria analítica a partir de ações com alunos do Ensino Médio, utilizando o software Geogebra na versão disponível para smartphones. Podemos mencionar, ainda, o estudo de Fernandes (2018), que investigou processos de aprendizagem de um conhecimento matemático vivenciados em espaços virtuais de uma disciplina ofertada na modalidade EaD.

A obra Parangolé, de Hélio Oiticica, dadas suas características de coautoria, unicidade e subjetividade, que discutiremos adiante, também tem orientado algumas discussões no âmbito educacional. Um dos principais articuladores do Parangolé no contexto da educação é Silva (2000), que propôs o conceito de Pedagogia do Parangolé que, por sua vez, supõe o conhecimento como algo aberto e imprevisível que deve ser construído de forma colaborativa e compartilhada. Esse conceito também norteou estudos como o de Castro (2012), que investigou processos de aprendizagem no campo da dança e contemporaneidade. No âmbito do uso de tecnologias digitais, a obra de 
Oiticica também tem sido objeto de reflexão em estudos como o de Jaime (2009), em que o autor propôs discussões estabelecendo paralelos entre o Parangolé e a produção de conhecimentos em uma aula virtual.

A seguir discutiremos com mais detalhes os elementos mencionados que orientaram a proposta teórica que discutimos neste artigo - o Ciclo de Ações Coletivo -, para análise de movimentos de aprendizagem com o uso de Lousa Digital. Os movimentos de aprendizagem aos quais nos referimos podem ser entendidos aqui como recortes dos processos de construção de conhecimento que vão ocorrendo a partir da interação entre alunos, professor e Lousa Digital em sala de aula. Vale abrir-se um parêntese para pontuar que consideramos interação a partir das ideias da Psicologia Cultural. Conforme discutiremos neste texto, Valsiner (2012) considera que a aprendizagem e o desenvolvimento do indivíduo se dão a partir de interações com o meio, nas quais o sujeito vivencia trocas de mensagens (informações) que ocorrem por intermédio de signos. Assim, ao falar em interação consideramos, portanto, que esta pode ocorrer entre sujeito e outros indivíduos, entre sujeito e objeto do conhecimento (mediada pela linguagem digital), entre sujeito e cultura, entre sujeito e tecnologia.

\section{Ciclo de Ações}

Ao falar em emprego de tecnologias digitais em contextos de ensino e de aprendizagem, consideramos na pesquisa um uso norteado pelo que Papert (2008) denominou abordagem construcionista, que é baseada na teoria construtivista de Piaget e supõe a utilização das tecnologias digitais de modo a oportunizar a construção de conhecimento pelo aluno em oposição à abordagem instrucionista, na qual a tecnologia é apenas meio para transmissão de informação. Pensando especificamente na Lousa Digital, consideramos um uso que possa oportunizar tais processos de construção de conhecimentos a partir da interação entre sujeitos. Conforme estabelecido na Psicologia Cultural (VALSINER, 2012), cada sujeito é único e possui conhecimentos únicos resultantes de suas relações histórico-culturais. Assim, cada encontro com o outro mostra-se como uma possibilidade de aprender e oportunizar aprendizagens.

Tomando as ideias de Seymour Papert como ponto de partida, Valente (2005) descreveu o processo de aprendizagem com o uso de computadores a partir do ciclo de ações (Descrição-Execução-Reflexão-Depuração), conforme mostra a Figura 1.

Figura 1 - Ciclo de ações que acontece na interação aprendiz-computador

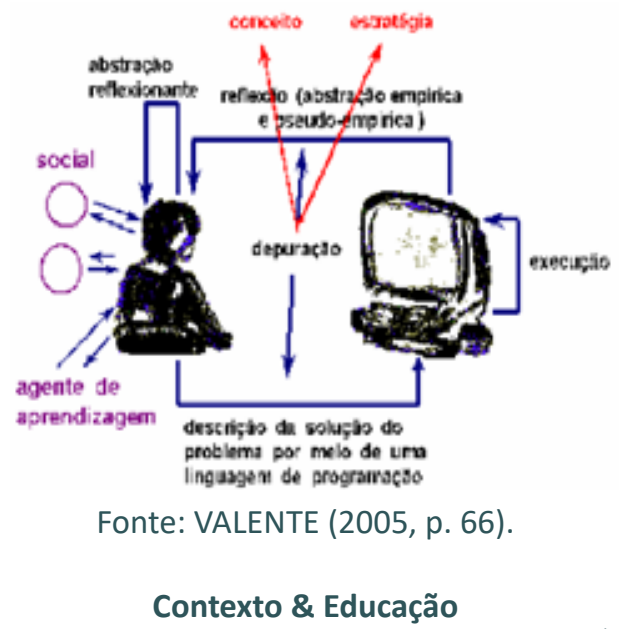

Editora Unijuí •ISSN 2179-1309 • Ano 36 • no 113 • Jan./Abr. 2021 
De acordo com os estudos de Valente (2005), é possível entender que durante o processo de aprendizagem com o uso de tecnologias digitais os sujeitos podem vivenciar as ações de descrição, execução, reflexão e depuração. A ação de descrição acontece quando o sujeito propõe, por meio da tecnologia e usando linguagem digital, uma possível solução para o problema proposto. O computador executa, então, o que foi descrito e apresenta na tela o resultado. A partir desse resultado é possível refletir sobre o que se visualiza na tela, caracterizando a ação de reflexão, e, caso não seja a solução desejada, o sujeito depura a solução e propõe uma nova descrição, iniciando um novo ciclo de ações. Nesse processo, a cada ciclo o sujeito (re)constrói conhecimentos, avançando em relação ao conhecimento que possuía anteriormente.

As ações de reflexão e depuração merecem certa atenção por serem estas as ações que, segundo Valente (2005), mais contribuem para o processo de construção de conhecimentos. A reflexão pelo fato de possibilitar a vivência de abstrações, extraindo-se informações e construindo conhecimentos a partir da interação com o objeto e reorganização de suas certezas prévias. Em uma perspectiva piagetiana, as abstrações provocam alterações na estrutura mental do sujeito, e ocorrem em diferentes níveis, conforme explica Valente (2005, p. 53):

O nível de abstração mais simples é a abstração empírica, que permite ao aluno extrair informações do objeto ou das ações sobre o objeto, tais como a cor e a forma do objeto. A abstração pseudo-empírica permite ao aprendiz deduzir algum conhecimento da sua ação ou do objeto. A abstração reflexiva permite a projeção daquilo que é extraído de um nível mais baixo para um nível cognitivo mais elevado ou a reorganização desse conhecimento em termos de conhecimento prévio (abstração sobre as próprias ideias do aluno).

A ação de depuração, por sua vez, merece atenção por possibilitar a assimilação de novas informações pelas estruturas mentais, reorganizando-as e transformando-as em novos conhecimentos.

Partindo das ideias de Valente (2005), em nossa pesquisa foi lançado um olhar sobre particularidades de processos de aprendizagem quando pensados sob a ótica de emprego de uma tecnologia digital de uso coletivo, ${ }^{3}$ no caso a Lousa Digital.

No Ciclo de Ações a ação de reflexão é vivenciada pelos sujeitos a partir da execução, ou seja, do retorno à descrição realizada apresentado na tela do computador. No uso da Lousa Digital vários sujeitos trabalham juntos, utilizando o mesmo computador ao mesmo tempo, seja indo até a Lousa e operando-a manualmente ou por meio de proposições orais. Nesse sentido, o retorno às proposições orais de cada um dos sujeitos pode ocorrer por ações dos demais envolvidos ao se pronunciarem, interagindo com as proposições anunciadas por outro colega, antes e depois de serem descritas no computador (nesse caso, na Lousa Digital).

Em outras palavras, durante um movimento de aprendizagem com Lousa Digital os sujeitos têm a possibilidade de vivenciar momentos de reflexão e depuração oportunizados pelas interações e retornos tanto com/da tecnologia digital quanto com/de

Empregaremos o termo "uso coletivo" para nos referirmos a um uso simultâneo da tecnologia, ou seja, situação em que muitos podem utilizar a mesma tecnologia, ao mesmo tempo, para resolver um único problema. 
outros participantes do processo. Desse modo, assumimos que ocorrem processos de construção coletiva de conhecimentos durante os quais cada participante envolvido no processo de resolução de um problema pode vir a ser sujeito dos/nos processos de produção individual e coletiva de descrição, reflexão e depuração, em movimentos contínuos de interação. Em outras palavras, cada indivíduo pode se tornar sujeito dos/nos processos de aprendizagem dos demais.

Outro aspecto a ser observado é a ação de depuração. Considerando as interações oportunizadas pela utilização de uma tecnologia digital de uso coletivo, os participantes do processo podem agir no sentido de depurar não somente suas próprias descrições, mas também as descrições (proposições) feitas pelos demais ou, ainda, realizadas de forma coletiva.

Essas observações apontam para um movimento de aprendizagem que, em decorrência de características de um uso da Lousa Digital de forma coletiva, se configura de uma maneira particular, diferenciando-se do processo descrito por Valente (2005), em especial nas ações de reflexão e depuração. A partir da possibilidade de os sujeitos envolvidos (ao vivenciarem as ações do ciclo proposto por Valente) participarem e interferirem nos ciclos de ações vivenciados pelos demais, as buscas por descrições que atendam às expectativas de cada um e de todos ao mesmo tempo, em busca de uma solução para o problema proposto, ocorrem no "mesmo espaço de tempo" usando a "mesma tela de computador".

As características e particularidades desses movimentos estão associadas à necessidade de se considerar outros elementos, de forma integrada aos elementos propostos por Valente (2005) no Ciclo de Ações. Tais elementos podem ser entendidos como fatores, para além da tecnologia e da interação com esta, que possuem relação direta e dialética com os processos de construção de conhecimento (com uso de tecnologias digitais) dos sujeitos. Referimo-nos à influência de diferentes interações entre sujeitos e o meio.

Em seus estudos sobre o Ciclo de Ações, embora não tenha sido objeto de suas pesquisas, Valente (2005) admite a presença dos fatores mencionados anteriormente e a influência destes nos processos de construção de conhecimento do sujeito. Na Figura 2, por exemplo, destacamos a presença de fatores sinalizados por Valente no ciclo, tais como o contexto social e a presença do agente de aprendizagem, que possuem relação direta com o processo de construção de conhecimento do sujeito quando do uso do computador.

Figura 2 - Presença de fatores externos ao sujeito no ciclo de ações

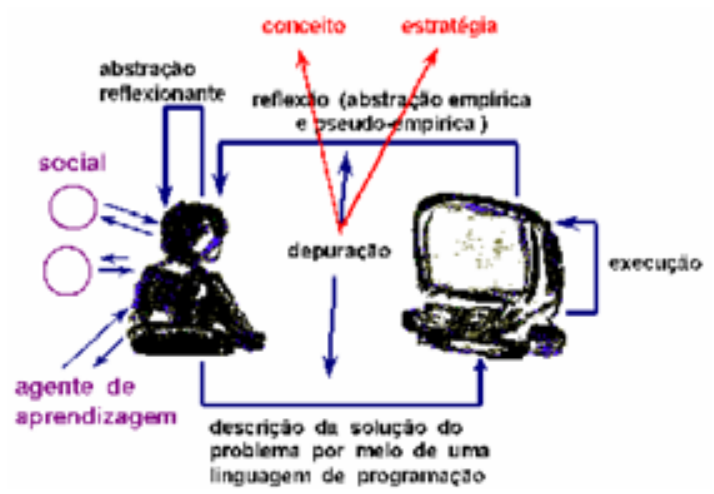

Fonte: Adaptado de VALENTE, 2005, p. 66 (destaque dos autores). 
Valente (2005) sinaliza que o termo "agente de aprendizagem" leva em consideração o papel do professor ao mediar situações de ensino e aprendizagem com uso de computadores, contribuindo para a existência e manutenção do Ciclo de Ações dos alunos. Em versões anteriores do Ciclo de Ações, é possível observar que o termo "agente de aprendizagem" era considerado por Valente como "mediador" na perspectiva de Vygotsky, como mostra a Figura 3.

Figura 3 - O ciclo de ações apresentado em 1998 e concepções teóricas que o embasam

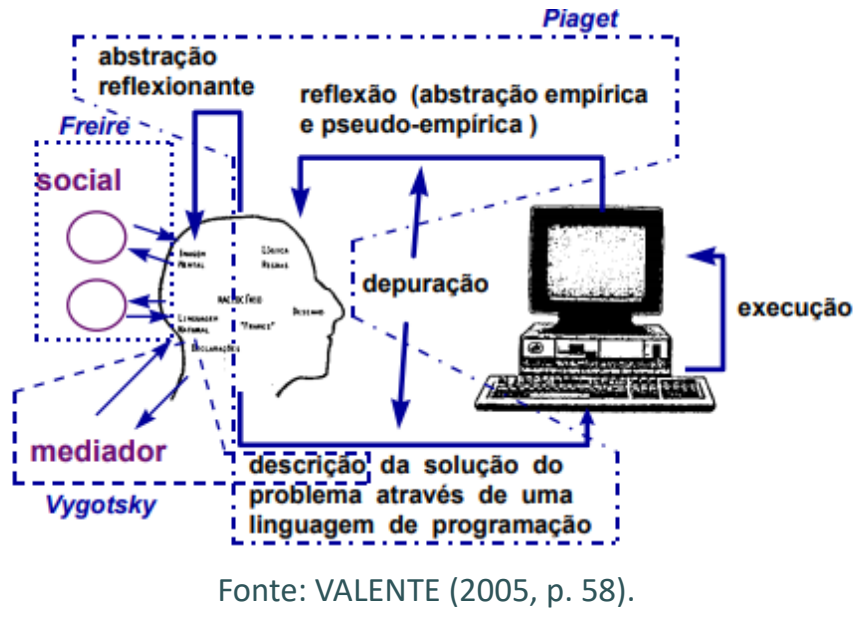

Nesse sentido, no contexto de nossa pesquisa damos destaque e ampliamos os estudos sobre o elemento fator social e o "agente de aprendizagem", discutindo e ampliando a influência desses elementos nos movimentos de aprendizagem dos alunos. Em momentos de aprendizagem com Lousa Digital, cada um dos participantes tem o potencial de assumir ativamente o papel de mediador, mediador dos processos de construção de conhecimentos de outros. O papel de agente de aprendizagem sinalizado por Valente (2005), fundamental para a manutenção dos ciclos de ações, portanto, deixa de ser assumido exclusivamente pelo professor e torna-se possível de ser assumido por qualquer sujeito envolvido nos movimentos de aprendizagem. Além disso, é importante considerar que cada um desses sujeitos age de acordo com suas vivências e histórias, seus conhecimentos e suas diferentes interações com o meio.

Nessa perspectiva, torna-se importante considerar, em movimentos de aprendizagem com o uso da Lousa Digital, os elementos discutidos anteriormente, uma vez que, no emprego dessa tecnologia digital supõe-se que as ações vivenciadas pelos sujeitos, no momento de resolução do problema com o uso da Lousa Digital, estejam articuladas e influenciadas com e pelas ações vivenciadas pelos demais. Assim, pode-se observar a existência de possíveis interseções entre ações dos Ciclos de Ações de cada sujeito em um grupo ao utilizar a Lousa Digital. Essas interseções irão constituindo, a cada movimento de resolução de um problema, o que chamamos de "Ciclo de Ações Coletivo", a articulação teórica que propomos ao observar e analisar movimentos de aprendizagem com Lousa Digital.

Para discutir esse processo, os estudos desenvolvidos por José Armando Valente são fundamentais, uma vez que tratam de processos de aprendizagem com o uso de computadores. Conforme, entretanto, discutido, pelas particularidades do uso da Lousa 
Digital optamos por considerar que a aprendizagem neste Ciclo de Ações Coletivo ocorre a partir de processos de construção coletiva de conhecimento, em que refletimos sobre a importância e a influência do "outro" nos processos de aprendizagem vivenciados pelos sujeitos.

Desse modo, discutimos, a seguir, alguns elementos dos estudos de Jaan Valsiner (2012) sobre a Psicologia Cultural, que apresentam aspectos importantes para compreender a proposta do Ciclo de Ações Coletivo que propomos.

\section{Psicologia Cultural}

A psicologia cultural tem suas ideias embrionárias na Perspectiva Coconstrutivista do Desenvolvimento Humano, conforme é possível observar em estudos anteriores de Jaan Valsiner, por exemplo, em Vasconcellos e Valsiner (1995). Nesse sentido, algumas ideias que trazemos a seguir sobre essa perspectiva, discutidas tanto por Vasconcellos e Valsiner (1995) quanto por Pinto e Maciel (2011), nos ajudam a explicitar nossa escolha pela Psicologia Cultural.

Na Psicologia Cultural temos como ponto de partida um sujeito que é concebido como um ser social que aprende e se desenvolve por meio de interações com o meio, embora essa aprendizagem e esse desenvolvimento sejam sempre individuais, próprios de cada sujeito. Nesse processo de interação com o meio, o sujeito vivencia constantemente trocas de mensagens/informações (que se dão por meio de signos) que, de acordo com Valsiner (2012), ocorrem a partir de um modelo bidirecional de transmissão cultural. Isso significa que, ao mesmo tempo em que o sujeito vai reconstruindo seu mundo intrapsicológico (sua cultura pessoal) a partir dessas trocas, interações, vai modificando ativamente o ambiente ao seu redor (cultura coletiva). Ou seja, ele transforma e é transformado, o tempo todo, pelo meio em que vive.

Nesse sentido, Vasconcellos e Valsiner (1995) chamam a atenção para o fato de que o modelo bidirecional de transmissão é um modelo dialógico, no qual não existem mensagens puras. As mensagens interiorizadas pelo sujeito, a partir das trocas com o meio, não são preservadas em sua totalidade, como se supõe no modelo unidirecional. Tais mensagens podem ser interiorizadas apenas em partes ou até mesmo enriquecidas pelo sujeito. De acordo com a Psicologia Cultural, isso ocorre em razão da individualidade dos sujeitos, que processam as trocas vivenciadas com o meio de maneira única e particular.

[...] a análise das questões subjetivas fica garantida, mesmo em situações de intersubjetividade, isto é, as características pessoais de cada indivíduo ficam respeitadas, mesmo na polifonia do emaranhado de influências sociais cotidianas (VASCONCELLOS; VALSINER, 1995, p. 21).

Isso significa que, mesmo vivenciando as mesmas situações, interagindo com as mesmas informações (mensagens), cada indivíduo, por meio de seus processos de internalização, constrói conhecimentos únicos, dada a individualidade de sua história, conhecimentos prévios e sistema psicológico. 
Sob a ótica da Psicologia Cultural, portanto, conforme é discutido por Pinto e Maciel (2011), o processo de construção de conhecimento é um processo complexo que envolve uma multiplicidade de fatores inter-relacionados, internos e externos ao sujeito, não sendo, portanto, passível de ser compreendido considerando apenas a influência de um único aspecto ou uma única perspectiva. Nessa mesma direção, Valsiner (2007) discute ainda que aprendizagem e desenvolvimento resultam de uma articulação entre processos biológicos e culturais, tornando-se essencial considerar tanto aspectos individuais quanto coletivos, o que, para Pinto e Maciel (2011, p. 230), "aponta para uma superação de entendimentos reducionistas em relação ao desenvolvimento humano, entendido de forma mais ampla e multidisciplinar".

Pelo fato de articular pressupostos das teorias de Piaget e Vygotsky, ainda de acordo com Pinto e Maciel (2011), essa perspectiva teórica acaba por evidenciar a gênese social da aprendizagem e do desenvolvimento humano. Nessa perspectiva, preza-se tanto pelo papel ativo do sujeito na construção de seus conhecimentos quanto pela importância do contexto social do qual faz parte.

Ao considerar aprendizagem e desenvolvimento a partir da perspectiva da Psicologia Cultural, admite-se, concordando com Valsiner (2012), que isso ocorre via processos simultâneos e dialéticos de internalização e externalização, a partir dos quais o sujeito vai reconstruindo seu mundo intrapsicológico. Esses processos, para Valsiner (2012, p. 283), servem como "para-choque contra a complexidade excessiva de mensagens sociais". Assim, diante da quantidade de informações trocadas constantemente com o meio, os processos de internalização e externalização garantem a individualidade do sujeito, fazendo com que a aprendizagem e o desenvolvimento de cada um aconteçam de maneira única e particular.

A internalização é entendida como o "processo de análise dos materiais semióticos existentes externamente e de sua síntese sob uma nova forma dentro do domínio intrapsicológico" (VALSINER, 2012, p. 283). Já a externalização, que é complementar e dialética à internalização, é concebida como

[...] o processo de análise dos materiais pessoal-culturais intrapsicologicamente existentes (subjetivos), durante sua transposição do interior da pessoa para seu exterior, e a modificação do ambiente externo como uma forma de nova síntese desses materiais. Os resultados da externalização entram imediatamente no domínio perceptual da pessoa e alimentam prospectivamente o processo de internalização (VALSINER, 2012, p. 283).

Esses dois processos - movimentos de internalização e externalização - são sempre construtivos. No caso da internalização, os materiais externos são transformados em formas internamente diversas. Na externalização "as sínteses produzidas no âmbito das ações da pessoa dentro do ambiente são novas em relação aos estados prévios do ambiente, e são diferentes dos materiais intrapsicológicos" (VALSINER, 2012, p. 283).

Internalização e externalização, portanto, são processos construtivos complementares que supõem uma ordem inversa quanto ao movimento da mensagem internalizada ou externalizada. Para Valsiner (2012), essa representação sequencial do processo de internalização e externalização mantém um paralelo ao modelo piagetiano de assimilação e acomodação. 
Pensando em movimentos de aprendizagem com o uso da Lousa Digital, ao vivenciarmos ações do Ciclo de Ações descrito por Valente, os processos de internalização e externalização de cada sujeito são alimentados, também, pelos processos de internalização e externalização dos demais, fazendo emergir um processo complexo, o "Ciclo de Ações Coletivo", que é constituído a partir das interações entre sujeitos e destes com a Lousa Digital ao realizarem uma tarefa.

Assim, ao propor ações com a Lousa Digital em sala de aula, norteadas por uma abordagem construcionista, pode ocorrer uma construção coletiva de conhecimentos e movimentos de aprendizagem a partir da interação entre indivíduos, destes com o objeto de estudo, com o software escolhido e a tecnologia da Lousa Digital. Esse movimento de aprendizagem afeta e é afetado, durante todo o movimento, pelos processos individuais de aprendizagem (internalizações e externalizações) de cada um dos participantes.

Durante a realização deste estudo e pesquisa, consideramos que a melhor maneira de representar esse Ciclo de Ações Coletivo seria a partir de Parangolés, metáfora que também representou vários movimentos da pesquisa realizada. Para que possamos melhor compreender o uso dessa representação, iremos, a seguir, dialogar um pouco sobre o "Parangolé", obra do artista plástico Hélio Oiticica.

\section{A metáfora do "Parangolé"}

O artista plástico Hélio Oiticica nasceu no Rio de Janeiro e criou, ao longo da carreira, trabalhos bidimensionais, relevos, capas, estandartes, dentre outros. No ano de 1964, levado por um amigo, Hélio passou a frequentar a comunidade da Mangueira, no Rio de Janeiro. A experiência ali vivenciada com a cultura da favela e as rodas de samba, foi determinante para a vida e obra do autor. $\mathrm{O}$ artista passou a usar a marginalidade social e a repressão política como inspiração e tema de suas obras na década de 60 , rompendo barreiras da cultura burguesa.

Nesse sentido, Hélio Oiticica começou a criar obras cujo objetivo era envolver o espectador por meio dos sentidos, fazendo com que este interagisse com a obra, desconstruindo a tão bem marcada divisão entre artista e espectador, e ressignificando o próprio conceito de arte. Foi nesse contexto que começou a surgir, em 1964, o Parangolé, chamado pelo próprio Hélio Oiticica de "antiarte 4 por excelência".

Parangolés são capas feitas de tecido ou de plástico para serem vestidas de maneiras diversas pelos participantes, estampadas com cores, palavras, fotos ou poemas interligados, que se revelam no movimento do participante que as veste.

Desse modo, as cores, antes contidas, tornam-se soltas e envolvem o corpo do participante que as faz brilhar no espaço por meio de danças e evoluções (SANTOS, 2008). Assim, conforme observado por Cavalcanti (2002)

Arte baseada em propostas antagônicas das formas tradicionais ou na rejeição total de práticas artísticas e valores estéticos consolidados. 
[...] a cor ganha um dinamismo no espaço através da associação com a dança e a música. A obra só existe plenamente, portanto, quando da participação corporal: a estrutura depende da ação. A cor assume, desse modo, um caráter literal de vivência, reunindo sensação visual, táctil e rítmica. O participante vira obra ao vesti-lo, ultrapassando a distância entre eles, superando o próprio conceito de arte.

Figura 4 - "Parangolés" Hélio Oiticica
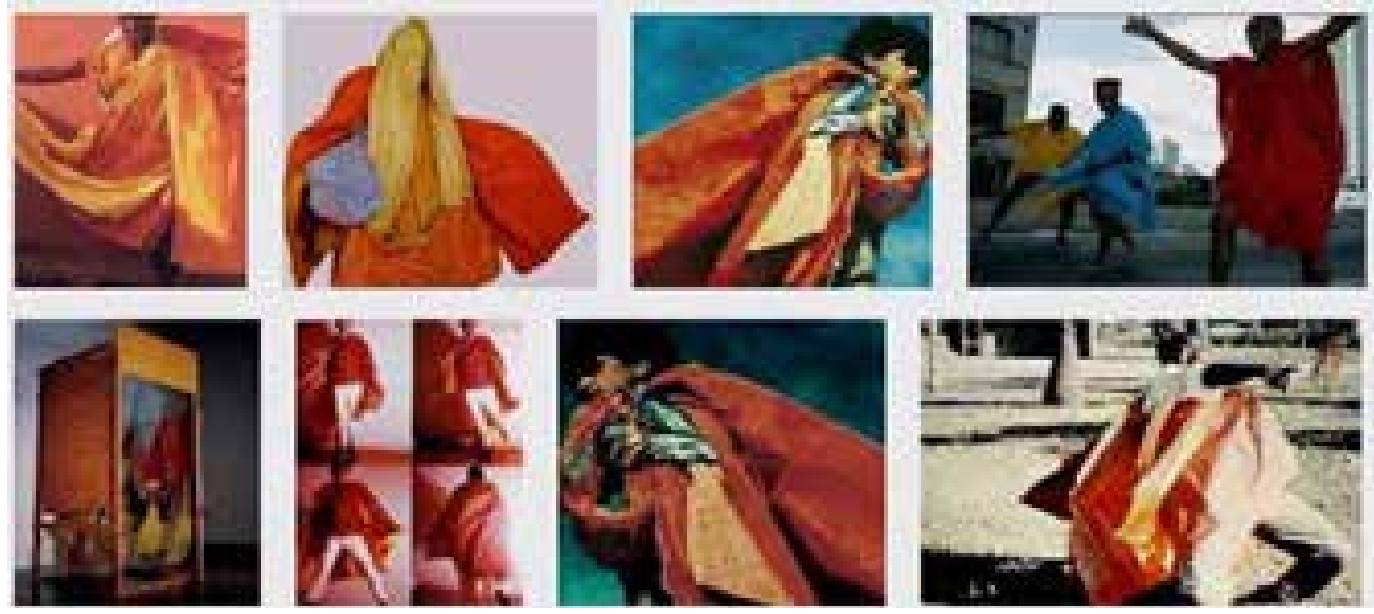

Fonte: SILVA, 2015

A proposta de Hélio Oiticica ao criar os Parangolés é de que o espectador saia da sua condição de espectador para a condição de participante, e, ao invés de contemplar as cores, vista-se delas. Na visão do artista não seria possível, portanto, ir a uma exposição de Parangolés. O Parangolé não é uma obra de arte, mas o "lugar" onde a experiência artística acontece.

No Parangolé, portanto, o motor ontológico é a capacidade de revelar a necessidade da ação. O vestir contrapõe-se ao assistir. Oiticica explica: " $O$ 'ato' do espectador ao carregar a obra revela a totalidade expressiva da mesma na sua estrutura: a estrutura atinge aí o máximo de ação própria no sentido do 'ato expressivo'. A ação é a pura manifestação expressiva da obra". Para que a ação aconteça, exige-se a participação inventiva e improvisada do expectador (CAVALCANTI, 2002).

Justino (1998) destaca que, com os Parangolés,

Oiticica mergulha na dimensão humana, que vai da ambiência das coisas e das idéias ao corpo, atingindo uma verdadeira dialética entre o dentro e o fora, a subjetividade e o coletivo. Dessa maneira, Hélio Oiticica põe-se criticamente contra o papel habitual do artista - o de criador único - e ignora as convenções sociais; elabora uma decomposição do velho arsenal das estruturas para compor o ambiente, desmontando o comportamento aprisionado, particularmente na contemplação e convenções, para atingir uma outra estrutura, uma decomposição da estrutura do comportamento. Os parangolés são, então, "programas" destinados a abrir o comportamento individual em direção ao coletivo. Dessa forma, enriquecem a experiência da vida.

Favaretto (1992) complementa afirmando que Hélio tinha a intenção de levar o indivíduo a dilatar suas capacidades artísticas, descobrir seu centro criativo e sua espontaneidade expressiva adormecida e condicionada pelo cotidiano. Nesse sentido, a obra 
vai além das intenções do artista. O Parangolé torna-se um lugar de experimentação ao invés de contemplação, o que nos leva a concordar com Silva (2015), quando assevera que o Parangolé se materializa enquanto experiência e se desmaterializa enquanto arte.

Fica claro, portanto, que o Parangolé se mostra como um rompimento das regras de generalização da expressão artística, dos conceitos de museus, exposições artísticas e galerias de arte. A arte acontece potencialmente na subjetividade do momento, dos gestos. Conforme apontado por Silva (2015), o Parangolé não é uma obra fechada no objeto artístico, mas, ao contrário, abre-se a todo momento para que sejam produzidos novos significados que jamais serão iguais àqueles produzidos no/pelo corpo do outro. Isso porque tal significação constitui-se para além de aspectos científicos, culturais ou estéticos, e fundamenta-se, sobretudo, nas vivências, sentidos, percepções e vontades. "A obra não acontece sozinha, ela acontece em cada um, no olho, no ouvido, na pele, nessa necessária presença do corpo que se modifica a todo instante, que é contingente, que me faz ser eu" (SILVA, 2015, p. 2).

É importante, entretanto, chamar a atenção para o fato de que a expressão artística do Parangolé, mesmo sendo esta fundamentada na subjetividade de cada participante, fica condicionada também a influências externas, ou seja, à percepção que cada um tem do ambiente do qual faz parte naquele momento.

O plano espaço-temporal objetivo da obra, o assistir, é dominado pelo subjetivo-vivencial do vestir. Numa fase intermediária, o participador vê o que se desenrola em outro, que veste outra obra. Nesta fase o espaço-tempo ambiental transforma-se numa totalidade "obra-ambiente", numa vivência de "participação coletiva" Parangolé (SANTOS, 2008, p. 531).

Desse modo, o Parangolé constitui-se uma expressão artística a partir da dialética entre a subjetividade dos movimentos e gestos de cada participante e os movimentos e coloridos que se formam na dança coletiva. Essa manifestação artística coletiva, portanto, influencia as manifestações individuais, e essas, por sua vez, ressignificam dialeticamente o coletivo.

Diante disso, conforme aponta Santos (2008), o Parangolé não deixa mais espaço para definições predeterminadas. A obra mostra-se infinita, livre de qualquer imposição de padrões estéticos. Livre, como nas palavras de Cavalcanti (2002), para "assumir-se como um objeto de experiência, anunciando, inclusive, o fim da instituição da autoria".

O que Oiticica propõe, portanto, é uma

[...] estética da existência, e não dos objetos; das formas de vida, não das formas de arte, sendo a obra apenas o ato de fazer a obra. Ou seja, uma ética do compromisso com formas constituídas de experiência, de libertação pessoal para a invenção de novas formas de vida (CAVALCANTI, 2002).

A metáfora do Parangolé representou, na pesquisa aqui discutida, a maneira como foram sendo vivenciadas e representadas as escolhas teóricas e metodológicas, a construção teórica e a realização das análises, bem como o processo de escrita da tese. Constituiu, ainda, os modos de se pensar e desenvolver pesquisa. Considerando o foco deste artigo, apresentaremos, a seguir, como a metáfora do Parangolé representou movimentos de Ciclos de Ações Coletivos propostos na pesquisa realizada. 


\section{PARANGOLÉS DE AÇÕES E CICLOS DE AÇÕES COLETIVOS}

Ao realizar uma tarefa, um problema, a ser resolvido com o uso de tecnologias digitais em um ambiente digital, a primeira ação que o sujeito pode vivenciar no Ciclo de Ações, conforme Valente (2005), é a descrição, na qual descreve uma possível solução para o problema em estudo a partir da linguagem do software utilizado. Com o uso da Lousa Digital, diferentes indivíduos de um grupo de trabalho podem anunciar proposições e propostas de descrição sem que, necessariamente, se tornem a descrição em si, aquela que será registrada na tela da Lousa. Será usado o termo proposta de descrição para diferenciar de descrição, sendo este último termo utilizado aqui, exclusivamente, para a descrição registrada e compartilhada na tela da Lousa Digital. Ou seja, a descrição conforme o Ciclo de Ações proposto por Valente.

Assim, ao externalizar uma primeira proposta de descrição, ou seja, uma possível solução para o problema em estudo, um indivíduo do grupo só iniciará o seu Ciclo de Ações, segundo proposto por Valente (2005), se a sua proposta for descrita e compartiIhada na Lousa Digital. Isto é, só se tornará uma descrição se todos do grupo concordarem com a proposta apresentada por esse indivíduo.

Ao externalizar a sua proposta de descrição, no entanto, esse indivíduo pode mobilizar outros a externalizarem suas proposições e propostas de descrição que, provavelmente, só o farão após refletirem sobre suas propostas até então "pensadas" e não externalizadas. Assim, ao afetar, e podendo ser afetado, pela proposição de outro, este primeiro indivíduo, ao externalizar sua proposta de descrição, inicia o que denominamos de "Ciclo de Ações Coletivo", que, diferente do Ciclo de Ações proposto por Valente, inicia sem interações diretas com o computador e sem uma descrição usando a linguagem digital do software escolhido, mas considerando essa linguagem um meio para produzir significados. A articulação teórica que propomos, portanto, o Ciclo de Ações Coletivo, que se constitui no uso da Lousa Digital, inicia-se tendo como primeira ação uma "proposta de descrição".

A partir da primeira proposta de descrição anunciada por um indivíduo, outros, que tenham pensado em propostas de descrição distintas ou complementares, mesmo sem externalizá-las, podem vivenciar reflexões sobre elas a partir do processo de internalização da primeira proposta externalizada.

Em seus estudos sobre o Ciclo de Ações, Valente (2005) discute que as reflexões podem levar o sujeito a vivenciar abstrações que, conforme mencionamos anteriormente, podem acontecer em diferentes níveis de abstração. Essas abstrações, em especial a abstração reflexionante, são parte fundamental do processo de construção de conhecimento que Piaget e Merlone (1976) explicam a partir da ideia de assimilação e acomodação.

Ao nos reportarmos à discussão de Valsiner (2012) sobre os processos de internalização e externalização, também discutidos anteriormente, vemos que esse pesquisador aponta um paralelo desses processos com a ideia de assimilação e acomodação piagetiana. Desse modo, entendemos que as reflexões são parte dos processos de internalização e externalização de cada indivíduo. 
A partir das reflexões vivenciadas é possível que um ou mais indivíduos depurem a proposta de descrição inicial e externalizem outras propostas de descrição, que podem oportunizar a indivíduos do grupo, inclusive ao autor da proposta inicial, vivenciar novas reflexões durante o processo de internalização das ideias que foram externalizadas por colegas do grupo a partir da depuração de sua primeira proposta de descrição.

Neste Ciclo de Ações Coletivo que se inicia, produzido pela e na interação entre indivíduos, os processos de aprendizagem, que são individuais, próprios de cada sujeito, podem ser afetados e podem afetar outros.

Nesse movimento de propostas de descrições é preciso chegar a uma descrição, uma proposta que seja resultado de um consenso dos indivíduos do grupo a ser inserida, executada por um software e compartilhada pela Lousa Digital. Até que isso aconteça, as ações vivenciadas pelos sujeitos envolvidos (propostas de descrição, reflexão, depuração) podem se interceptar e os movimentos de internalização e externalização de cada um podem influenciar, de diferentes maneiras, os processos de internalização e externalização de outros.

Vale ressaltar, todavia, que não é possível determinar quais indivíduos do grupo refletiram e internalizaram mensagens, de que maneira o fizeram, bem como quais propostas externalizadas influenciaram em seus processos de aprendizagem. Isso porque, concordando com Valsiner (2012), o acesso às internalizações só é possível via alguma forma de externalização. Assim, tais processos só podem ser observados na medida em que externalizações forem ocorrendo. Ou seja, pensando no uso da Lousa Digital em sala de aula, só poderemos analisar aspectos de processos de aprendizagem de alunos que externalizam os seus movimentos de internalização enquanto vivenciam um Ciclo de Ações Coletivo.

Considerando as interações entre os processos de aprendizagem vivenciados pelos sujeitos, na Figura 5 sugerimos uma representação para esse movimento; representação que, levando em conta a metáfora discutida, chamamos de "Parangolé de Ações".

Figura 5 - Um Parangolé de ações

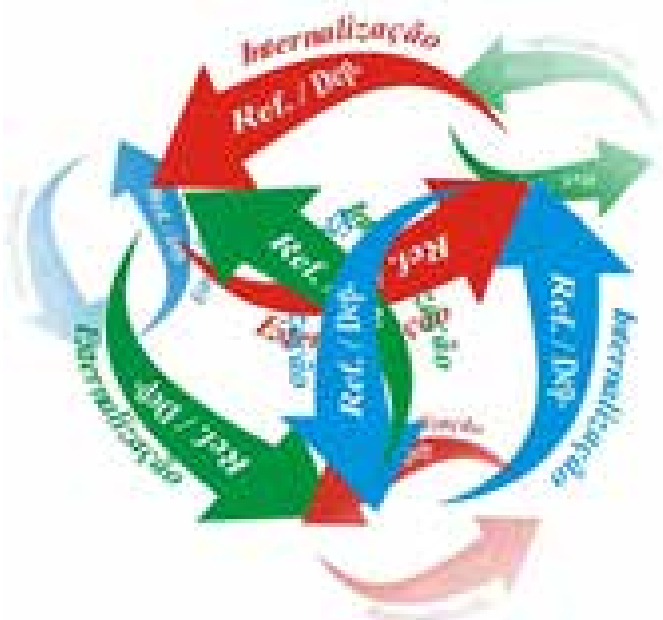

Fonte: CARVALHO, 2019.

Contexto \& Educação

Editora Unijuí •ISSN 2179-1309 • Ano 36 • no 113 • Jan./Abr. 2021 
Na Figura 5 consideramos movimentos de ações de reflexões (ref.) e de depuração (dep.) de diferentes indivíduos (cada cor representa um indivíduo diferente na ação) no processo coletivo de construção de conhecimento, mobilizadas por processos de internalização e que podem provocar movimentos de externalização.

É importante observar, contudo, que se trata apenas de uma sugestão de representação, uma vez que a Figura não é capaz de expressar em sua totalidade o processo que ocorre a partir das interações entre os sujeitos. Isso porque não se trata de um processo estático. Não é possível determinar quantos e quais sujeitos estarão participando em cada momento, de que maneira ou por quanto tempo. Nesse sentido, não se pode prever o que será externalizado por eles e, portanto, como ações de cada sujeito poderão influenciar ações de internalização e externalização de outros, e de que forma isso ocorrerá.

Assim, a cada momento podemos ter participação de indivíduos distintos se afetando de maneiras diversas e, nesse sentido, a cada situação esse Parangolé de Ações que propomos para representar os movimentos de interação entre sujeitos pode ganhar "desenhos" diferentes. Além de "desenhos" distintos, que ganham forma a partir dos movimentos dos sujeitos participantes, propomos também a representação das ações de cada indivíduo em cores diferentes, de modo que, a cada Parangolé de Ações, a partir de variadas participações, sejam revelados "coloridos" únicos, as cores de cada movimento de interação, as cores de cada Parangolé de Ações.

A opção pelo termo Parangolé de Ações leva em consideração tanto a dinamicidade do processo, descrita anteriormente, quanto a subjetividade do sujeito que olha para o mesmo. Pensando nessa dinamicidade, assim como na obra de Oiticica os significados produzidos em/por um corpo jamais serão iguais aos produzidos em/por outro (SILVA, 2015), no Parangolé de Ações as representações serão sempre únicas, uma vez que os sujeitos se modificam a cada interação e, portanto, não são os mesmos a cada movimento. Nunca teremos, assim, um movimento de aprendizagem igual a outro.

Com relação ao sujeito que olha para este processo, considerando a visão de sujeito proposta pela Psicologia Cultural, mesmo que o Parangolé de Ações represente aqui uma possibilidade de articulação de elementos para analisar movimentos de aprendizagem com Lousa Digital, cada pesquisador, professor ou leitor, de modo geral, o fará de maneira única a partir das internalizações vivenciadas na/pela interação com os elementos aqui apresentados. Assim, diferentes olhares podem ser lançados por distintas pessoas ou por uma mesma pessoa em variados momentos para situações de aprendizagem com Lousa Digital, mesmo que esses olhares se constituam a partir da articulação de elementos apresentada nesse texto.

Nesse sentido, podemos considerar que a representação proposta na Figura 5 se mostra apenas como uma "capa" de Parangolé. O Parangolé, de fato, se dá no movimento, na ação; movimento este que estará sempre condicionado à subjetividade de quem lê, ouve, observa, analisa, propõe ou participa de movimentos de aprendizagem com Lousa Digital. 
A representação da capa do Parangolé de ações da Figura 5 se deu a partir de movimentos que podem ocorrer em um grupo de indivíduos ao vivenciarem a primeira ação (um primeiro Parangolé de Ações) do que estamos chamando de Ciclo de Ações Coletivo, as proposições de descrição, até que uma primeira descrição consensual seja registrada no software e compartilhada na tela da Lousa Digital.

Ao descrever na tela da Lousa Digital uma possível solução para o problema proposto, ação de "descrição", também prevista no Ciclo de Ações proposto por Valente (2005), o software realiza, então, a ação de "execução", executando a descrição realizada e apresentando um retorno, que é único, para todos os alunos do grupo.

Mesmo, entretanto, com um resultado único retornado pela tecnologia, pelo software, cada participante pode visualizá-lo e vivenciar processos de "reflexão" e "depuração" a partir deste retorno do software, e o faz de maneira única e individual, de acordo com os seus processos de internalização. Tratando-se, contudo, de ações individuais, isso ocorre em um tempo comum (após observarem a tela da Lousa), em movimentos síncronos, com objetivo comum, o que nos leva a considerar que essas ações se configuram, também, como ações coletivas do grupo de alunos envolvidos na resolução do problema, uma vez que são síncronas e podem ser recorrentes.

As ações de "reflexão" e de "depuração" dos sujeitos no Ciclo de Ações Coletivo, portanto, também previstas no Ciclo de Ações proposto por Valente, diferenciam-se deste último pelo aspecto coletivo que adquirem, mesmo tratando-se de ações mentais individuais. Tais ações, se externalizadas via mensagens do indivíduo que reflete e/ou depura, implicam movimentos contínuos de internalização e externalização e vão, portanto, alimentando o Ciclo de Ações Coletivo. A partir das reflexões e ações de depuração, cada sujeito pode propor novas propostas de descrição, caso o retorno dado pela tecnologia não seja o esperado para um ou mais indivíduos do grupo como solução para o problema em estudo.

As ações de reflexão e depuração, sendo ações mentais de cada sujeito, só são possíveis de ser acessadas a partir de externalizações. Pensando no Ciclo de Ações Coletivo, é possível que essas externalizações ocorram tanto no sentido de propor, de imediato, uma nova proposta de descrição, quanto de discutir/refletir sobre/depurar o resultado da descrição observado em tela. Em ambos os casos tem-se a possibilidade de vivenciar um novo Parangolé de Ações. Isso porque as proposições anunciadas por um ou mais indivíduos, mesmo não sendo novas propostas de descrição, voltam a influenciar os processos de internalização e externalização dos sujeitos a partir da interação entre os mesmos, até que surjam novas propostas de descrição.

É possível vivenciar no grupo, logo após a visualização da execução realizada pelo software e projetada na tela da Lousa Digital, portanto, um novo Parangolé de Ações, cuja capa pode ser representada como a que apresentamos na Figura 5. Nesse movimento pode-se chegar a uma nova descrição, que é inserida no software e compartiIhada pela tela da Lousa Digital, que determina uma nova execução e novas reflexões e depurações, novos Parangolés, até que se tenha em tela um resultado aceitável pelo grupo. Esse movimento, caracterizado pelas ações "Parangolé de Ações (Proposições de 
descrição/reflexão/depuração) - Descrição - Execução - Parangolé de Ações (reflexões/ depurações/proposições de descrição) - Nova Descrição...", é o que estamos chamando de Ciclo de Ações Coletivo.

A Figura 6 apresenta uma proposta de representação para esse Ciclo. Vale lembrar que cada Parangolé de Ações é uma experiência única e, assim, a capa do Parangolé, exposta na Figura 6, é apenas um indicativo de que naquele momento ocorrem vivências de Parangolés de Ações. A cada Ciclo teremos novos Parangolés vivenciados e, portanto, diferentes capas e distintas representações.

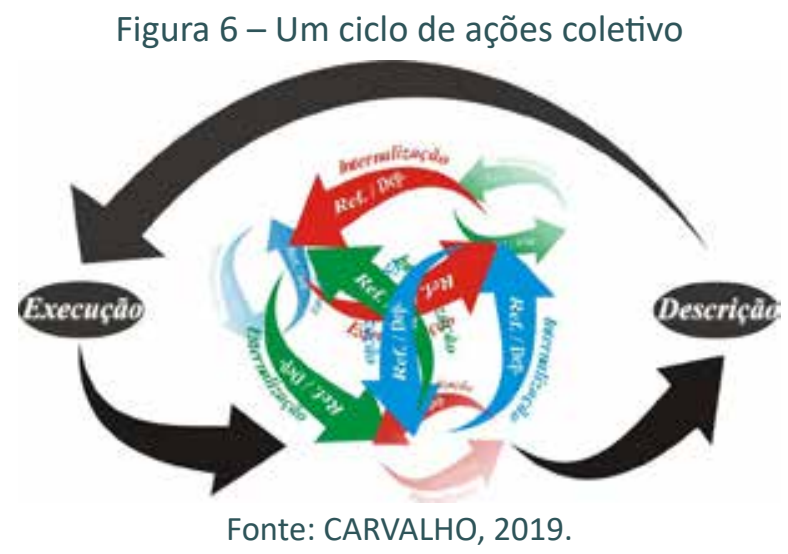

Vale ressaltar, ainda, que, assim como proposto nos estudos de Valente (2005) sobre Ciclo de Ações, a cada descrição levada à tela da Lousa Digital os conhecimentos dos sujeitos não são mais os mesmos.

Nesse sentido, portanto, além de os Parangolés serem vivenciados de maneira única dentro de um Ciclo, nunca vivenciando a mesma experiência, o mesmo ocorre de um ciclo para outro. A cada Ciclo de Ações Coletivo que vai se constituindo a partir de uma nova Descrição, o movimento de interação entre sujeitos, destes com a Lousa Digital e com o objeto de estudo, na resolução de um problema vai tomando formas e cores diferentes, ao mesmo tempo em que os conhecimentos são (re)construídos continuadamente, observadas as singularidades de cada sujeito. Tentamos representar esse movimento na Figura 7.

Figura 7 - Ciclos de ações coletivos

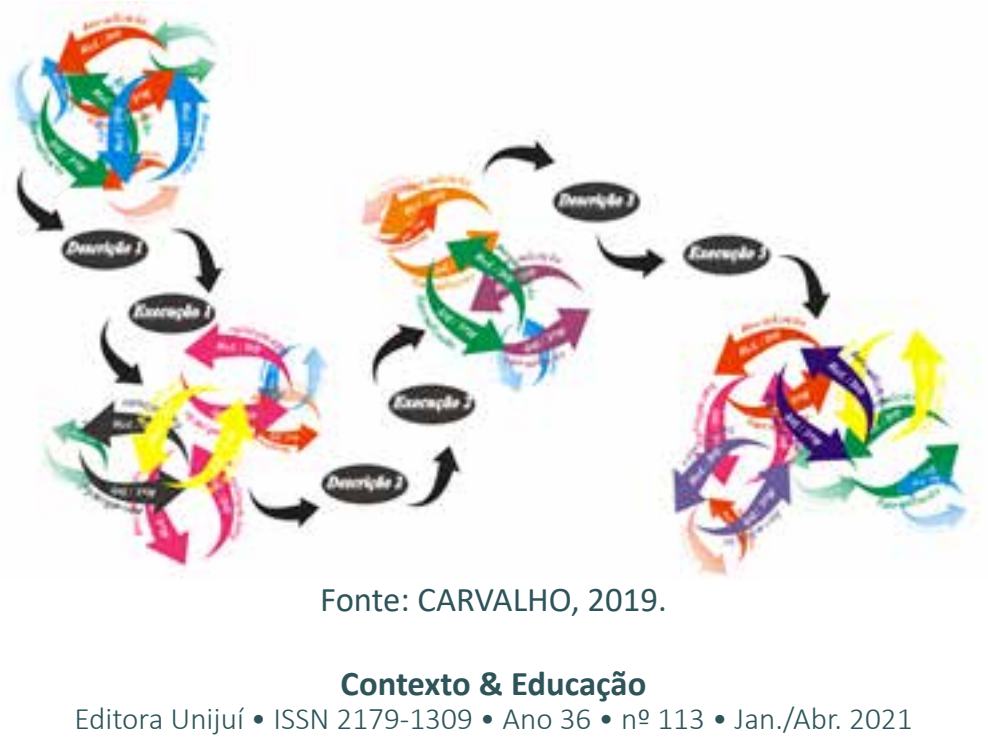


Ao propor análises de movimentos de aprendizagem a partir de Ciclos de Ações Coletivos aqui apresentados, ressaltamos alguns pontos importantes. Inicialmente, é preciso observar que se trata de processos de aprendizagem de sujeitos distintos, porém, usando de maneira síncrona a mesma tecnologia. Isso faz com que algumas ações do ciclo, conforme discutido, sejam coletivas (comuns a todos os sujeitos envolvidos) e outras individuais, próprias de cada sujeito. Nesse sentido, desde as observações de Ciclos de Ações Coletivos vivenciados por um grupo, é possível analisar, a partir de externalizações de indivíduos do grupo, movimentos coletivos e individuais de aprendizagem e como estes movimentos se afetam.

A descrição que vai para a tela da Lousa Digital, assim como a ação de execução, é comum para todos os sujeitos, ou seja, só é possível levar à tela da Lousa Digital uma única descrição por vez, que implicará em um único retorno acessível a todos, fornecido pelo computador. O que sugerimos nesta proposta teórica, no entanto, é que a descrição levada à tela seja resultado de um complexo processo de interação entre sujeitos, um Parangolé de Ações. Esse é constituído a partir de propostas de descrições, reflexões e depurações, quando os processos individuais de construção de conhecimento dos indivíduos participantes do processo, que parcialmente são externalizados, podem influenciar e ser influenciados pelos processos individuais de outros. Mesmo os processos de indivíduos que nada externalizam durante a vivência do Ciclo em um grupo, podem ser influenciados pelo Parangolé de Ações. Para ter acesso aos processos de internalização desses indivíduos, no entanto, teríamos de propor outras ações de externalização.

Outro ponto a ser ressaltado é que as ações de reflexão e depuração, assim como nos estudos de Valente (2005), são individuais e próprias de cada sujeito. A partir destas, porém, diferente de um Ciclo de Ações individual, no qual cada sujeito realiza uma nova descrição, desencadeia-se um Parangolé de Ações pelas externalizações dessas ações, até que se chegue a uma nova descrição a ser realizada na tela da Lousa Digital.

Diante do exposto, consideramos importante investigar os movimentos de aprendizagem que constituem Parangolés de Ações e que produzem descrições que são registradas e compartilhadas na tela de uma Lousa Digital, cujo software (ou softwares) executa. Defendemos a ideia de que a análise desses movimentos possibilita investigar algumas particularidades de processos de aprendizagem que podem ser mobilizados em sala de aula, com o emprego de um único computador, representado pela Lousa Digital, usado por um grupo de forma síncrona.

As análises realizadas na pesquisa, portanto, discutido aqui um dos resultados, tiveram como foco movimentos coletivos de aprendizagem que constituem Parangolés de Ações, suas cores e formas em cada grupo, cada momento, a cada problema a ser resolvido, e a articulação destes com as ações de descrição e execução dos Ciclos de Ações Coletivos.

\section{ALGUMAS CONSIDERAÇÕES}

Os coloridos e formas dos muitos Parangolés que podem ser vivenciados, e foram observados ao longo desta pesquisa, que não se repetem, nos possibilitaram concluir que cada movimento de aprendizagem foi único, porque se constituiu a partir de interações entre sujeitos que, por sua vez, são diferentes a cada interação. 
Sobre os coloridos e formas, estes possuem relação direta com as interações vivenciadas no processo de aprendizagem com uso da Lousa Digital. Ou seja, na medida em que mais alunos se sentiram encorajados a externalizar suas ideias, conhecimentos e reflexões, ao usarem a Lousa Digital, na perspectiva teórica discutida, mais interações puderam ser realizadas e mais reflexões essas interações puderam influenciar.

Podemos afirmar que, assim como uma "expressão coletiva parangolé" ganhou vida na proporção em que mais indivíduos entraram na dança, os movimentos que constituíram os Parangolés de Ações e os Ciclos de Ações Coletivos se intensificaram quando mais alunos externalizaram suas proposições e questões ao interagirem com colegas, com o professor e com o objeto de estudo, a partir de ações realizadas e compartilhadas na/pela Lousa Digital. Nesse sentido, foi possível observar a constituição de Parangolés representados por capas maiores, menores, mais ou menos coloridas...

Tudo o que foi possível observar, entretanto, só se tornou acessível pelas externalizações. Melhor dizendo, para que os Parangolés ganhassem vida e cores foi necessário que os sujeitos se permitissem influenciar e serem influenciados pelos movimentos que ali ocorreram, externalizando reflexões, depurações, ideias. Desse modo, o professor será desafiado a propor estratégias para mobilizar os alunos a externalizar conhecimentos em razão do fato de alguns não exporem suas ideias, sendo esta uma das dificuldades observadas na análise de dados empíricos produzidos na pesquisa (CARVALHO, 2019).

Sinalizamos, ainda, que as interações não ocorrerem por si só. De fato, observamos que a característica da Lousa Digital, de possibilitar o compartilhamento de ideias, favorece os processos de interação entre indivíduos. As interações, contudo, resultam das características da Lousa Digital associadas às ações dos alunos e escolhas e ações do professor: escolha dos softwares ou aplicativos e das tarefas, que podem ou não favorecer diálogos, questionamentos e reflexões. Desse modo, o professor tem papel fundamental na constituição e vivência dos Parangolés de Ações com o uso da Lousa Digital, assim como cada um dos participantes.

O desafio da vivência dos Ciclos de Ações Coletivos, propostos na pesquisa, é investir em estratégias para que ocorram mais externalizações. São estratégias que possam favorecer a vivência de diferentes interações e processos de aprendizagem, para que se constituam, em aulas com uso da Lousa Digital, Parangolés cada vez mais coloridos.

\section{REFERÊNCIAS}

CARVALHO, Sérgio Freitas de. Parangolés de ações e Lousa Digital: movimentos de aprendizagem em aulas de matemática. 2019. 176 f. Tese (Doutorado em Educação Matemática) - Universidade Federal de Mato Grosso do Sul, Campo Grande, 2019.

CASTRO, Juliana Fernandez. Dança, educação e interatividade: por uma “pedagogia do parangolé". 2012. 84 f. Dissertação (Mestrado em Dança) - Universidade Federal da Bahia, Salvador, 2012.

CAVALCANTI, Jardel Dias. Parangolé: anti-obra de Hélio Oiticica. Digestivocultural, São Paulo, p. 1, 2002. Disponível em: https://www.digestivocultural.com/colunistas/coluna.asp?codigo=856\&titulo=Parangole:_anti-obra_de_Helio_Oiticica. Acesso em: 12 jun. 2017.

FAVARETTO, Celso Fernando. A invenção de Hélio Oiticica. São Paulo: Edusp, 1992. 
FERNANDES, Frederico Fonseca. Ambiente virtual e educação a distância: espaços e movimentos de aprendizagem em uma disciplina. 2018. 194 f. Tese (Doutorado em Educação) - Universidade Federal de Mato Grosso do Sul, Campo Grande, 2018.

JAIME, Rafael Rocha. Comunicação, educação e tecnologias: Notas para um cenário contemporâneo, 2009. Disponível em: http://www.bocc.ubi.pt/_esp/autor.php?codautor=1733. Acesso em: 30 abr. 2020. JUSTINO, Maria José. Seja marginal, seja herói: modernidade e pós modernidade em Hélio Oiticica. Curitiba: Ed. da UFPR, 1998. Disponível em: http://www.itaucultural.org.br. Acesso em: 7 jun. 2017.

OLIVEIRA, Ádamo Duarte de. Linguagem digital, celulares e geometria analítica: encontros com alunos do Ensino Médio. 2019. 223 f. Tese (Doutorado em Educação Matemática) - Universidade Federal de Mato Grosso do Sul, Campo Grande, 2019.

PAPERT, Seymour. A máquina das crianças: repensando a escola na era da informática. Tradução Sandra Costa. Porto Alegre: Artmed, 2008.

PIAGET, Jean; MERLONE, Marion. A equilibração das estruturas cognitivas: problema central do desenvolvimento. Rio de Janeiro: Zahar, 1976.

PINTO, Viviane Fernandes Faria; MACIEL, D. A. Interações criança-criança e a coconstrução da linguagem: uma análise qualitativa. Revista Diálogo Educacional, v. 11, n. 32, p. 225-245, 2011.

RESSURREIÇÃO, Sueli Barros; SAMPAIO, Sônia Maria da Rocha. Transições e reconfigurações do self de jovens indígenas na experiência universitária. Psicologia Escolar e Educacional, São Paulo, v. 21, n. 3, p. 495504. 2017. Disponível em: http://www.scielo.br/pdf/pee/v21n3/2175-3539-pee-21-03-495.pdf. Acesso em: 20 fev. 2018.

SANTOS, Nívia Valéria. A vanguarda em Hélio Oiticica: uma revolução no conceito estrutural de obra de arte. In: ENCONTRO DE HISTÓRIA DA ARTE, 4., 2008. IFCH - Unicamp, 2008. Disponível em: https://www. ifch.unicamp.br/eha/atas/2008/DOS\%20SANTOS,\%20Nivia\%20Valeria\%20-\%20IVEHA.pdf. Acesso em: 15 jun. 2017.

SILVA, Marco. Pedagogia do Parangolé: novo paradigma em educação presencial e online. In: SILVA, Marco (org.). Sala de aula interativa. Rio de Janeiro: Ed. Quartet, 2000.

SILVA, Paula F. Parangolés e pós-modernidade: corpos envolvidos, corpos envolventes. Revista Intercâmbio dos Congressos de Humanidades, n. 16, 2015.

VALSINER, Jaan. Mundos da mente, mundos da vida: fundamentos da psicologia cultural. Porto Alegre: Artmed, 2012.

VALSINER, Jaan. Culture in minds and societies: foundations of cultural psychology. New Delhi: Sage, 2007. VALENTE, José Armando. A espiral da espiral de aprendizagem: o processo de compreensão do papel das tecnologias de informação e comunicação na educação. 2005. Tese (Livre Docência) - Universidade Estadual de Campinas, Campinas, 2005.

VASCONCELLOS, Vera Maria Ramos de; VALSINER, Jaan. Perspectiva co-construtivista na psicologia e na educação. Porto Alegre: Artmed, 1995. 